\title{
Influência de doses de calcário com diferentes relações cálcio:magnésio na produção de matéria seca e na composição mineral da alfafa ${ }^{(1)}$
}

\author{
Fernando Teixeira Gomes ${ }^{(2)}$, Arnaldo Chaer Borges ${ }^{(3)}$, Júlio César Lima Neves ${ }^{(4)}$ e Paulo Cezar Rezende Fontes ${ }^{(5)}$
}

\begin{abstract}
Resumo - A acidez dos solos brasileiros, com alumínio em níveis tóxicos e baixa disponibilidade de elementos essenciais, principalmente o fósforo, exige aplicações de calcário e fertilizantes para a adequada utilização agrícola. Este trabalho objetivou avaliar o efeito de quatro doses de calcário calculadas com base no teor de $\mathrm{Al}^{3+}$ trocável do solo e em cinco relações molares de Ca: $\mathrm{Mg}$, na produção de matéria seca e na composição mineral da alfafa. Duas cultivares de alfafa, Flórida 77 e Crioula, foram cultivadas em Latossolo Vermelho-Amarelo álico, textura argilosa, em casa de vegetação, em esquema fatorial disposto no delineamento inteiramente casualizado, com quatro repetições. A produção de matéria seca da parte aérea das duas cultivares aumentou em razão do aumento das doses de calcário, e somente a cultivar Flórida 77 apresentou diferenças significativas entre as relações molares Ca:Mg. Os teores de $\mathrm{Ca}, \mathrm{Mg}$ e $\mathrm{N}$ na matéria seca da parte aérea, de modo geral, aumentaram em razão do aumento na quantidade de calcário, sendo somente os teores de Ca e Mg alterados pelas diferentes relações molares de Ca:Mg. Os teores de $\mathrm{P}$ e $\mathrm{K}$, de modo geral, apresentaram pequenos decréscimos com a elevação das doses de calcário, embora considerados satisfatórios para a nutrição da alfafa.
\end{abstract}

Termos para indexação: Medicago sativa, calagem, nutriente, teor em matéria seca, fertilidade do solo.

\section{Influence of limestone rates with different calcium:magnesium ratios on shoot dry matter yield and mineral composition of alfalfa}

\begin{abstract}
Acidic Brazilian soils presenting toxic aluminum levels, plus low essential elements availability, specially phosphorus, demand limestone and fertilizers application for adequate agricultural use. The effect of four limestone rates, based on soil $\mathrm{Al}^{3+}$ concentrations and five $\mathrm{Ca}: \mathrm{Mg}$ ratios on the shoot dry matter yield and mineral composition of two alfalfa cultivars (Florida 77 and Crioula), cultivated in an alic Red-Yellow Latosol, clayish texture was evaluated, under greenhouse conditions. A factorial scheme in a completely randomized design with four repetitions was used. The shoot dry matter yield of both cultivars increased with the rates of limestone, but only the cultivar Florida 77 showed significant differences among $\mathrm{Ca}: \mathrm{Mg}$ ratios. Concentrations of $\mathrm{Ca}, \mathrm{Mg}$ and $\mathrm{N}$ in the shoots dry matter, in general, increased in response to applied limestone, but only the $\mathrm{Ca}$ and $\mathrm{Mg}$ altered by the different $\mathrm{Ca}: \mathrm{Mg}$ ratios. Values for $\mathrm{P}$ and $\mathrm{K}$, showed small decreases with the increase in limestone rates, although still satisfactory for alfalfa nutrition.
\end{abstract}

Index terms: Medicago sativa, liming, nutrients, dry matter content, soil fertility.

\section{Introdução}

A alfafa (Medicago sativa L.) é uma forrageira perene que apresenta elevado valor nutritivo, exce-

\footnotetext{
(1) Aceito para publicação em 15 de julho de 2002.

(2) Embrapa-Centro Nacional de Pesquisa de Gado de Leite, Rua Eugênio do Nascimento, 610, Dom Bosco, CEP 36038-330 Juiz de Fora, MG. Bolsista do CNPq. E-mail: ftgomes@bol.com.br

(3) Universidade Federal de Viçosa (UFV), Dep. de Microbiologia, Av. P. H. Rolfs, s/no, CEP 36570-000 Viçosa, MG. E-mail: chaer@mail.ufv.br

(4) UFV, Dep. de Solos. E-mail: julio@solos.ufv.br

(5) UFV, Dep. de Fitotecnia. E-mail: pacerefo@ufv.br
}

lente palatabilidade e digestibilidade. Por ser uma planta rica em minerais, exige boas condições de fertilidade do solo, sendo muito sensível à acidez e à baixa disponibilidade de nutrientes (Nuernberg et al., 1990). Nos estados de Goiás, Mato Grosso, Mato Grosso do Sul e Minas Gerais, os solos predominantes são os Latossolos, caracteristicamente ácidos, pobres em bases, especialmente de $\mathrm{Ca}$ e de $\mathrm{Mg}$ e alta saturação de $\mathrm{Al}$ (Lopes \& Cox, 1977). Em tais condições, a aplicação de calcário é prática rotineira recomendável para superar essas limitações, aumentando a disponibilidade da maioria dos nutrientes para as plantas e diminuindo o Al e Mn trocáveis no solo (Malavolta et al., 1997). Os calcários calcíticos con- 
têm, em média, $45 \%$ de $\mathrm{CaO}$, e os dolomíticos, em média, $20 \%$ a $40 \%$ de $\mathrm{CaO}$ e $10 \%$ a $20 \%$ de $\mathrm{MgO}$ (Malavolta, 1980). Em decorrência da baixa quantidade de $\mathrm{MgO}$ existente nos calcários calcíticos, o uso sistemático de tais calcários afeta a relação Ca:Mg no solo (Fassbender \& Bornemisza, 1994).

Assim, a quantidade e a qualidade do calcário a ser aplicado é fundamental para plantas leguminosas como a alfafa, visto que a dose de calcário a ser aplicada deve ser ajustada aos requerimentos tanto da planta quanto do rizóbio (Muchovej et al., 1986).

Muitos trabalhos não são conclusivos na determinação da relação molar Ca:Mg no calcário ou no solo com a finalidade de se obter melhor produtividade. Segundo Hunter (1949), citado por Halstead et al. (1958), a produção de matéria seca da alfafa não foi alterada, em razão das variações nas relações molares Ca:Mg de 1:4 a 32:1. Em soja, Muchovej et al. (1986) observaram que a produção de matéria seca da parte aérea não foi estatisticamente diferente para as relações molares Ca: $\mathrm{Mg}$ variando de 0,26:1 a 24:1. Relações molares Ca:Mg de 1:1 a 267:1 não influenciaram significativamente a produção da alfafa e do trevo (Reid, 1996). Moreira et al. (1999) verificaram que a alfafa, cultivar Crioula, não respondeu significativamente às diferentes relações molares $\mathrm{Ca}: \mathrm{Mg}$ do corretivo da acidez do solo.

No entanto, é importante avaliar mudanças na composição de nutrientes no tecido vegetal causadas pelo aumento da dose de calcário com diferentes relações molares de $\mathrm{Ca}: \mathrm{Mg}$.

O objetivo deste trabalho foi avaliar o efeito da quantidade e da qualidade de calcário em Latossolo Vermelho-Amarelo álico, na produção de matéria seca e composição mineral da alfafa.

\section{Material e Métodos}

O ensaio foi realizado em casa de vegetação, e o solo utilizado $(0-20 \mathrm{~cm})$ foi um Latossolo Vermelho-Amarelo álico, textura argilosa, localizado no Município de Viçosa, MG, com as seguintes características químicas: $\mathrm{pH}_{\text {(água) }}$ 4,6; 2,5 e 46,8 $\mathrm{mg} \mathrm{dm}^{-3}$ de P e K, respectivamente, e 0,6, $0,2 \mathrm{e} 1,2 \mathrm{cmol}_{\mathrm{c}} \mathrm{dm}^{-3} \mathrm{de} \mathrm{Ca}^{2+}, \mathrm{Mg}^{2+} \mathrm{e} \mathrm{Al}^{3+}$, respectivamente. Os tratamentos consistiram de duas cultivares de alfafa (Flórida 77 e Crioula), quatro doses de calcário calculadas com base no teor de $\mathrm{Al}^{3+}$ trocável do solo (Kamprath,
1967), multiplicado pelos fatores 1,2 , 4 e 6 , e cinco relações molares, em porcentuais de Ca:Mg: 100:0, 75:25, 50:50, 25:75 e 0:100. Utilizou-se um esquema fatorial disposto no delineamento inteiramente casualizado, com quatro repetições.

As fontes de $\mathrm{Ca}$ e $\mathrm{Mg}$ utilizadas foram, respectivamente, o $\mathrm{CaCO}_{3}$ e $\mathrm{MgCO}_{3}$ (p.a.), misturados em subamostras de $12 \mathrm{dm}^{3}$ de solo secado ao ar, passado em peneira com malha de $2 \mathrm{~mm}$. Em seguida, foi adicionada água destilada para elevar a umidade a $60 \%$ da capacidade de campo (Silva, 1986). O solo com calcário foi incubado em sacos de plástico até a obtenção de valores constantes de pH. Foi, então, novamente secado ao ar e passado em peneira com malha de $2 \mathrm{~mm}$. Cada subamostra foi dividida em porções de $2,8 \mathrm{dm}^{3}$ de solo e acondicionadas em vasos de plástico.

Soluções de macronutrientes foram misturadas a cada subamostra, antes da semeadura, de modo a fornecer, 60, 40 e $450 \mathrm{mg} \mathrm{dm}^{-3}$ de K, S e P, respectivamente. Soluções de micronutrientes foram parceladas eqüitativamente em duas aplicações, sendo a primeira antes da semeadura e a segunda após 30 dias, visando fornecer o total de 0,813 , $3,664,4,0,1,329,0,15$ e $1,556 \mathrm{mg} \mathrm{dm}^{-3} \mathrm{de} \mathrm{B}, \mathrm{Mn}, \mathrm{Zn}, \mathrm{Cu}$, Mo e Fe, respectivamente (Alvarez Venegas, 1974).

Após a desinfestação superficial das sementes por imersão em etanol $75 \%$, por um minuto, e em peróxido de hidrogênio $6 \%$ (v:v), por dez minutos, procedeu-se a lavagem em água destilada estéril (Vincent, 1970), e inoculação de Sinorhizobium meliloti e a imediata semeadura nos vasos. Após sete dias da emergência, foi feito o desbaste, deixando-se três plântulas por vaso.

A irrigação foi efetuada diariamente com água destilada, procurando-se manter, através da pesagem dos vasos, a umidade do solo próxima a $60 \%$ da capacidade de campo. Setenta dias após a semeadura, a parte aérea foi cortada a $8 \mathrm{~cm}$ do solo, colocada em sacos de papel e secadas a $65^{\circ} \mathrm{C}$, por 72 horas. A colheita coincidiu com o florescimento completo das plantas. As determinações de $\mathrm{N}$ na matéria seca da parte aérea foram realizadas após a digestão sulfúrica, pelo método colorimétrico de Nessler (Cataldo et al., 1974). Após a digestão nítrico-perclórica das amostras da matéria seca da parte aérea (Johnson \& Ulrich, 1959), os teores de $\mathrm{Ca}$ e $\mathrm{Mg}$ foram determinados por espectrofotometria de absorção atômica, os de K, por fotometria de emissão de chama e, os de P, por colorimetria, segundo Braga \& Defelipo (1974).

Os dados obtidos foram submetidos à analise de variância a 5\% de probabilidade pelo teste $\mathrm{F}$. A produção de matéria seca e os teores de $\mathrm{Ca}, \mathrm{Mg}, \mathrm{N}, \mathrm{P}$ e K foram submetidos à análise de regressão, sendo usados os valores de 100, 75, 50 e 25 nas relações molares Ca:Mg nos cálculos das equações. 


\section{Resultados e Discussão}

Não foram efetuadas as determinações de matéria seca da parte aérea e dos teores de $\mathrm{Ca}, \mathrm{Mg}, \mathrm{N}, \mathrm{P}$ e K das plantas do tratamento com a relação 0:100, (correspondente à dose de calcário de 7,2 t ha ${ }^{-1}$ ), em razão da morte das plântulas aos 20 dias após a semeadura. Provavelmente, o grande desbalanço entre a concentração de $\mathrm{Ca}^{2+} \mathrm{e} \mathrm{Mg}^{2+}$ tenha provocado a morte dessas plantas. Segundo Lund (1970), altas concentrações de $\mathrm{Mg}^{2+}$ em relação ao $\mathrm{Ca}^{2+}$ reduzem o crescimento da soja, principalmente pelo efeito da composição na absorção. No presente trabalho, na relação molar Ca:Mg 0:100, os baixos teores de $\mathrm{Ca}^{2+}$ existentes no solo, provavelmente, não foram suficientes para possibilitar o crescimento das plantas. Além disso, Reid (1996) observou que a alfafa apresenta a capacidade de concentrar altos teores de $\mathrm{Mg}^{2+}$. Assim, a alta disponibilidade de $\mathrm{Mg}^{2+}$ no solo, na dose de 7,2 t ha-1 de calcário, na relação molar $\mathrm{Ca}: \mathrm{Mg}$ de 0:100, pode ter causado toxidez e, conseqüentemente, provocado a morte das plantas.

A produção de matéria seca da parte aérea da cultivar Flórida 77 aumentou de forma linear com o aumento das doses de calcário, em todas as relações Ca:Mg (Figura 1), demonstrando a sensibilidade dessa cultivar às variações das doses de calcário e, em menor escala, das relações molares Ca:Mg. Reid (1996) e Su \& Evans (1996) também obtiveram aumentos significativos na produção de matéria seca da parte aérea de alfafa em doses crescentes de calcário. No entanto, não observaram alterações entre as diferentes relações molares $\mathrm{Ca}: \mathrm{Mg}$ presentes no calcário.

Em razão da maior produção de matéria seca da parte aérea na relação 100:0, a cultivar Flórida 77 mostrou maior sensibilidade aos baixos teores de $\mathrm{Ca}^{2+}$ no solo do que aos de $\mathrm{Mg}^{2+}$. $\mathrm{O}$ baixo teor de $\mathrm{Mg}^{2+}$ no solo não prejudicou a produção de matéria seca da parte aérea. A linearidade do modelo indica que doses de calcário superiores a 7,2 t ha-1 seriam necessárias para obtenção da produção máxima (Figura 1). Portanto, essa cultivar apresenta-se altamente exigente em $\mathrm{Ca}$, ou possui maior sensibilidade à acidez do solo.

A produção de matéria seca da parte aérea da cultivar Crioula ajustou-se ao modelo quadrático de re- gressão e foi influenciada apenas pelas doses de calcário, não havendo efeito significativo das relações molares de Ca:Mg. Por esse modelo a dose de calcário de 6,9 t ha-1 é adequada para a obtenção da produção máxima (Figura 1). Em alfafa, cultivar Crioula, Moreira et al. (1999) observaram alterações na produção de matéria seca em razão das doses crescentes de calcário, não obtendo respostas significativas às diferentes relações molares $\mathrm{Ca}: \mathrm{Mg}$ do calcário. A ausência de resposta da cultivar Crioula às relações molares de $\mathrm{Ca}: \mathrm{Mg}$ sugere que a mesma seja mais tolerante a baixos níveis de $\mathrm{Ca}^{2+}$ no solo do que a cultivar Flórida 77. Essa característica da cultivar Crioula, provavelmente, se deve ao fato de ela ter surgido por um processo de seleção natural, sob condições ambientais adversas e solos de baixa fertilidade (Honda \& Honda, 1990).
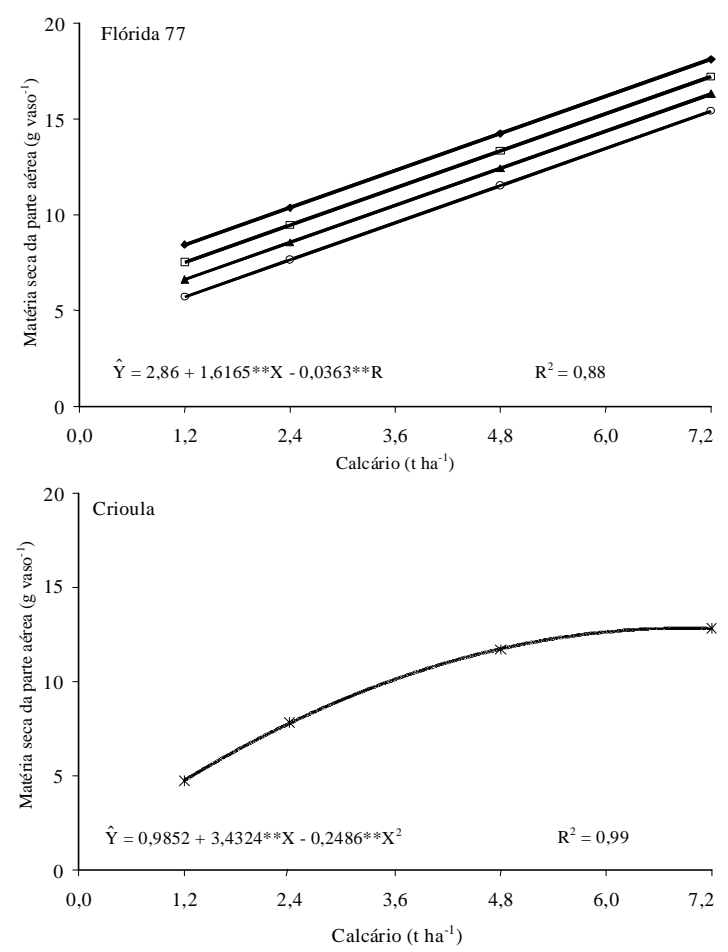

Figura 1. Matéria seca da parte aérea de alfafa, cultivares Flórida 77 e Crioula, aos 70 dias após a semeadura, em razão das doses de calcário $(\mathrm{X})$ e das relações molares $(\mathrm{R})$ de Ca:Mg ( : 100:0; $\square: 75: 25 ; \boldsymbol{\Delta}: 50: 50 ;$ o: 25:75) aplicados ao solo. $* *$ Significativo pelo teste $\mathrm{t}$, a $1 \%$ de probabilidade. 
A menor dose de calcário utilizada proporcionou teores de $\mathrm{Ca}^{2+}+\mathrm{Mg}^{2+}$ no solo, antes do plantio, de 1,4 a $2,1 \mathrm{cmol}_{\mathrm{c}} \mathrm{dm}^{-3}$. Esses teores são considerados baixos pelo critério da Comissão de Fertilidade do Solo do Estado de Minas Gerais (Alvarez Venegas \& Ribeiro, 1999). Por esse critério, considerando-se a alfafa como cultura exigente em calagem, deveriam ser aplicadas 5,8 $\mathrm{t} \mathrm{ha}^{-1}$ de calcário que proporcionariam aproximadamente $98 \%$ da produção máxima de matéria seca da parte aérea para a cultivar Crioula. Entretanto, em relação à cultivar Flórida 77, a maior produção de matéria seca da parte aérea foi obtida com a aplicação de 7,2 t ha-1 de calcário.

Quanto aos teores de $\mathrm{Ca}$ e $\mathrm{Mg}$ na matéria seca da parte aérea, de ambas cultivares, ajustou-se o modelo quadrático de regressão, observando-se efeitos significativos tanto das doses de calcário como das relações molares de Ca: $\mathrm{Mg}$ (Figuras 2 e 3).
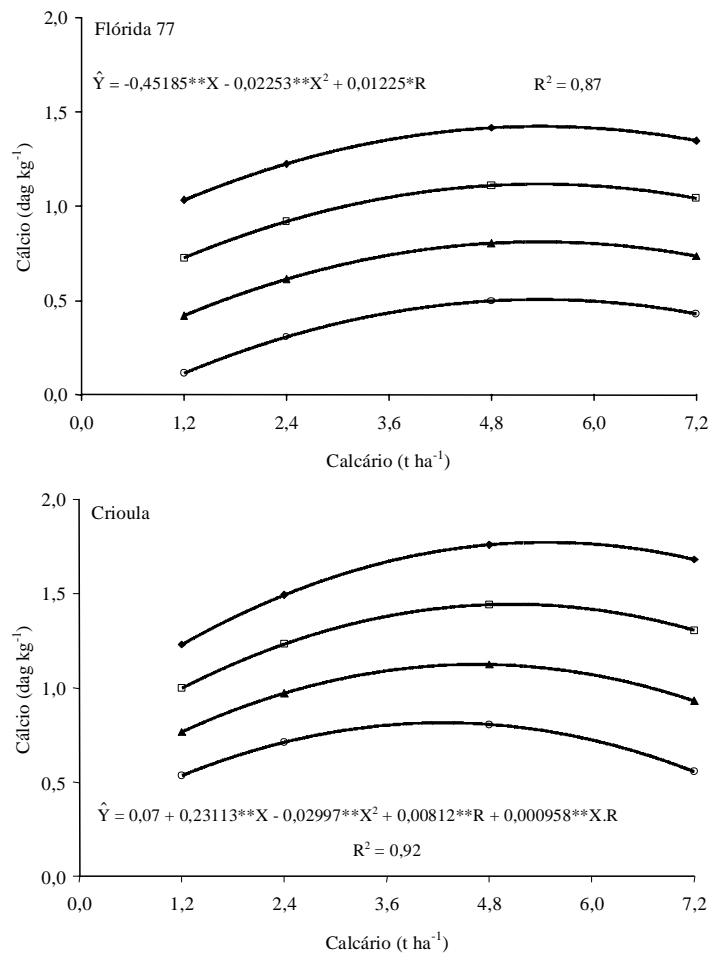

Figura 2. Teores de cálcio na parte aérea de alfafa, cultivares Flórida 77 e Crioula, aos 70 dias após a semeadura, em razão das doses de calcário $(\mathrm{X})$ e das relações molares $(\mathrm{R})$ de Ca: $\mathrm{Mg}(\bullet: 100: 0 ; \square: 75: 25 ; \mathbf{\Lambda}: 50: 50 ;$ o: 25:75) aplicados ao solo. * e**Significativo pelo teste t, a $5 \%$ e $1 \%$ de probabilidade, respectivamente.
Os teores de Ca na matéria seca da parte aérea das duas cultivares, de modo geral, mostraram-se menores na dose mais baixa de calcário, variando de 0,11 a 1,76 dag kg$^{-1}$ (Figura 2). Esse resultado está de acordo com os de Pinkerton et al. (1997), que encontraram teores médios de Ca na matéria seca da parte aérea na faixa de 1,0 a 2,0 dag kg-1 considerada adequada em período de florescimento. No campo, Oliveira \& Corsi (1987) constataram que o teor médio de Ca na matéria seca da parte aérea de quatro cultivares de alfafa foi de 1,48 dag kg-1. Fageria et al. (1989) e Muchovej et al. (1993) também obtiveram aumentos significativos nos teores de $\mathrm{Ca}$ em plantas de alfafa e soja, respectivamente, em razão de incrementos nas doses de calcário.

Semelhantemente ao Ca, os teores de $\mathrm{Mg}$ na matéria seca da parte aérea em ambas as cultivares, de
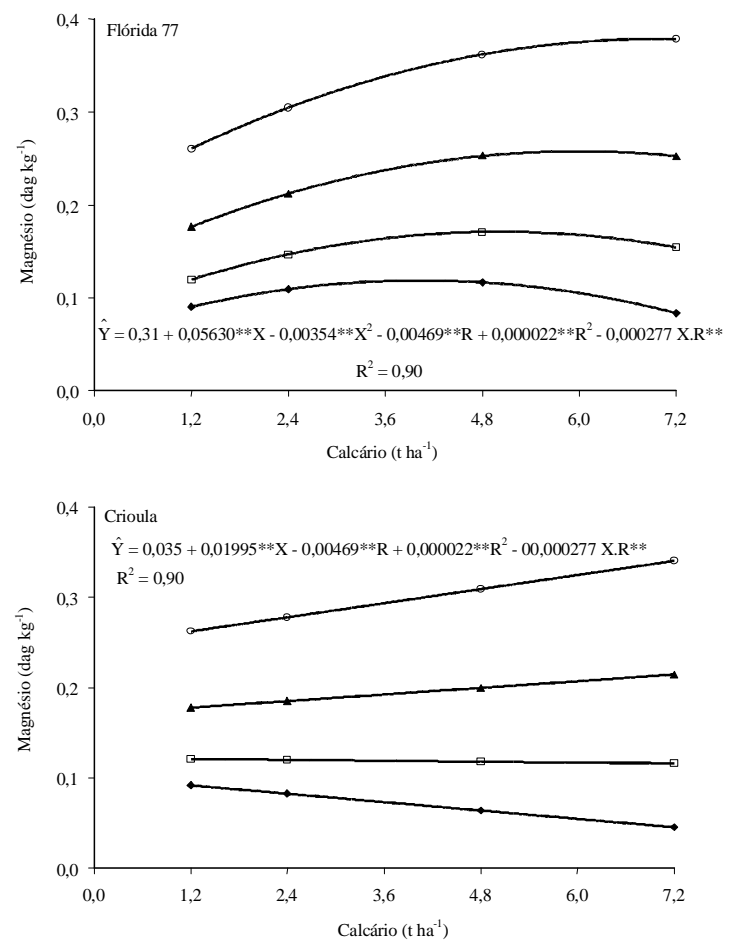

Figura 3. Teores de magnésio na parte aérea de alfafa, cultivares Flórida 77 e Crioula, aos 70 dias após a semeadura, em razão das doses de calcário $(\mathrm{X})$ e das relações molares (R) de Ca:Mg ( : 100:0; $\square: 75: 25 ; \boldsymbol{\Delta}:$ 50:50; o: 25:75) aplicados ao solo. **Significativo pelo teste $\mathrm{t}$, a $1 \%$ de probabilidade. 
modo geral, mostraram-se menores na dose mais baixa de calcário, exceto na cultivar Crioula, na relação 100:0. Nessa relação, houve redução dos teores de $\mathrm{Mg}$ à medida que aumentou a dose de calcário. Os teores de $\mathrm{Mg}$ encontrados neste trabalho variaram de 0,04 a 0,37 dag kg-1 . De modo geral, esses teores ficaram abaixo do nível crítico de $0,35 \mathrm{dag} \mathrm{kg}^{-1}$ (Martins et al., 1990). Moreira et al. (1999), cultivando alfafa em solo em casa de vegetação, com diferentes doses de calcário e relações molares Ca:Mg, também observaram teores de $\mathrm{Mg}$ nas diferentes relações, superiores aos encontrados neste trabalho, com teor médio de $0,39 \mathrm{dag} \mathrm{kg}^{-1}$.

Os teores de $\mathrm{Ca}$ e $\mathrm{Mg}$ também foram alterados pelas diferentes relações molares de $\mathrm{Ca}: \mathrm{Mg}$, sendo que os teores de Ca diminuíram à medida que se aumentou a participação do $\mathrm{Mg}$ no calcário. Moreira et al. (1999) também constataram alterações nos teores de $\mathrm{Ca}$ e $\mathrm{Mg}$ em diferentes relações $\mathrm{Ca}: \mathrm{Mg}$. Segundo Moore et al. (1961), o Ca e o Mg na solução do solo são antagônicos, ou seja, o excesso de um prejudica a absorção do outro.

Com base nos teores de $\mathrm{Ca}$ e $\mathrm{Mg}$ na parte aérea, deduz-se que a eficiência de utilização desses nutrientes foi menor na cultivar Crioula que na cultivar Flórida 77. É possível que o nível crítico de ambos os nutrientes seja mais baixo para a cultivar Flórida 77 que para a Crioula. Incrementos nos teores desses nutrientes refletiram em aumentos na produção da matéria seca da parte aérea (Figura 1).

Em relação aos teores de $\mathrm{N}$ nas duas cultivares, ajustou-se o modelo quadrático base raiz quadrada de regressão para doses de calcário em cada relação molar Ca: $\mathrm{Mg}$ (Figura 4). Os teores de $\mathrm{N}$ na porção superior da parte aérea da alfafa variaram de 2,6 a $3,7 \mathrm{dag} \mathrm{kg}^{-1}$ e foram considerados adequados por Kelling \& Matocha (1990). Portanto, os teores de N na matéria seca da parte aérea da alfafa podem ser considerados como satisfatórios, com exceção no tratamento com a da menor dose de calcário, em todas as relações. Os teores máximos estimados de N, nas médias das relações molares de $\mathrm{Ca}: \mathrm{Mg}$, seriam obtidos com 4,73 $\mathrm{t} \mathrm{ha}^{-1}$ (cv. Crioula) e 5,34 $\mathrm{t} \mathrm{ha}^{-1}$ (cv. Flórida 77).

Os teores de P na matéria seca da parte aérea, de modo geral, decresceram com a elevação da dose de calcário (Figura 5). Essa diminuição pode ser atribuída à elevada produção de matéria seca da parte aérea nas doses mais altas de calcário (Figura 1), promovendo diluição desse elemento no tecido da planta, visto que o seu conteúdo aumentou com a quantidade de calcário aplicada. Os teores de $\mathrm{P}$ na matéria seca da parte aérea, nas duas cultivares, encontraram-se na faixa de 0,24 a 0,44 dag kg-1 (Figura 5), considerada satisfatória para a nutrição da alfafa. O teor médio de $\mathrm{P}$ na matéria seca da parte aérea de alfafa, obtido por Oliveira \& Corsi (1987), foi

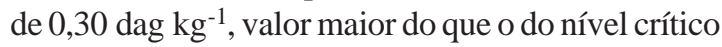
de $0,24 \pm 0,1 \mathrm{dag} \mathrm{kg}^{-1}$, estabelecido por Andrew \& Robins (1969) e Moreira (1997).

Os teores de K na matéria seca da parte aérea nas duas cultivares situaram-se na faixa de 2,13 a 3,14 dag kg$^{-1}$ (Figura 6), e podem ser considerados suficientes para a nutrição da alfafa, tendo em vista
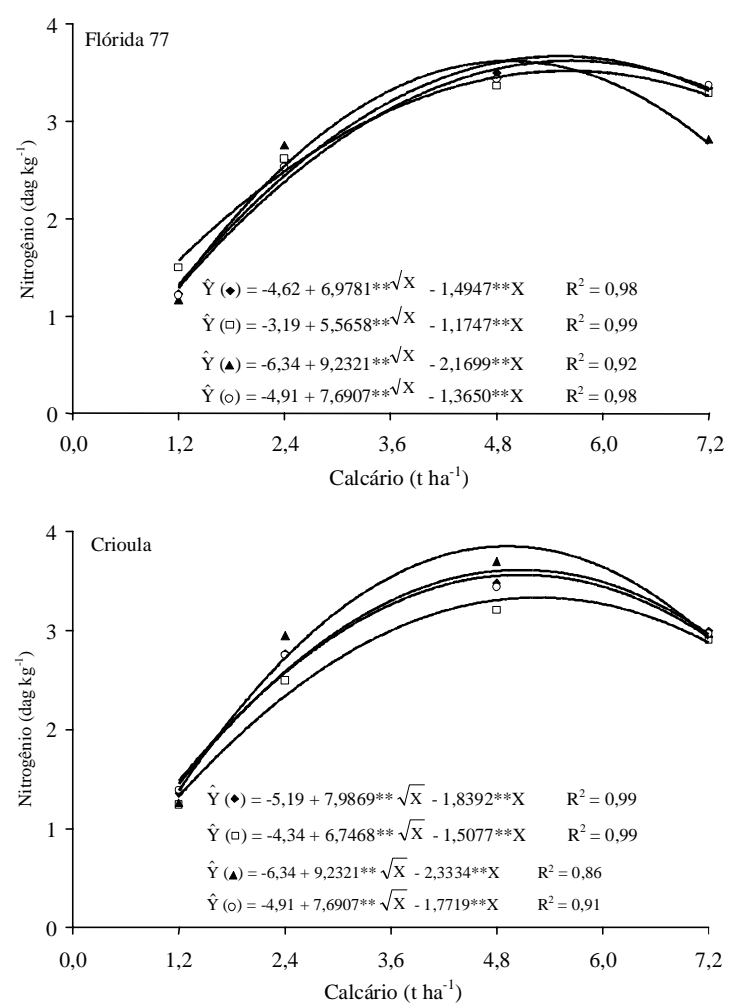

Figura 4. Teores de nitrogênio na parte aérea de alfafa, cultivares Flórida 77 e Crioula, aos 70 dias após a semeadura, em razão das doses de calcário $(\mathrm{X})$ e das relações molares de Ca:Mg ( $\bullet$ 100:0; $\square: 75: 25 ; \boldsymbol{\Delta}:$ 50:50; o: $25: 75)$ aplicados ao solo. $* *$ Significativo pelo teste $\mathrm{t}$, a $1 \%$ de probabilidade. 
que os valores considerados adequados variam de 2,0 a 3,5 dag $\mathrm{kg}^{-1}$ no início de florescimento (Pinkerton et al., 1997). Oliveira \& Corsi (1987) encontraram o teor médio de $\mathrm{K}$ de $2,89 \mathrm{dag} \mathrm{kg}^{-1}$ na matéria seca da parte aérea de diversas cultivares de alfafa. De modo geral, observou-se ligeiro decréscimo no teor de $\mathrm{K}$ com o aumento da dose de calcário (Figura 6). É provável que esse decréscimo tenha ocorrido em razão da elevada produção de matéria seca da parte aérea nas doses mais altas de calcário, o que causou diluição do nutriente na planta, já que o conteúdo de $\mathrm{K}$ aumentou com a quantidade de calcário aplicado ao solo. Resultados semelhantes foram obtidos com alfafa (Halstead et al., 1958) e com soja (Muchovej et al., 1993).
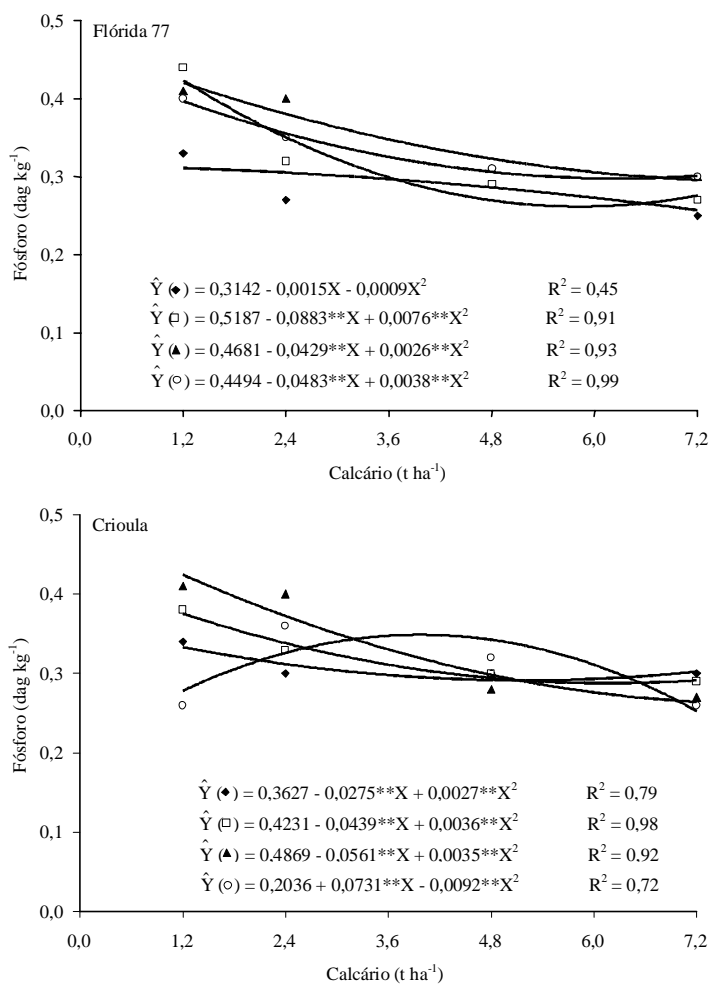

Figura 5. Teores de fósforo na parte aérea de alfafa, cultivares Flórida 77 e Crioula, aos 70 dias após a semeadura, em razão das doses de calcário $(\mathrm{X})$ e das relações molares de Ca: $\operatorname{Mg}(\bullet: 100: 0 ; \square:$ 75:25; $\mathbf{\wedge}: 50: 50 ;$ o: 25:75) aplicados ao solo. ${ }^{* * S i g n i f i c a t i v o ~ p e l o ~ t e s t e ~ t, ~ a ~} 1 \%$ de probabilidade.
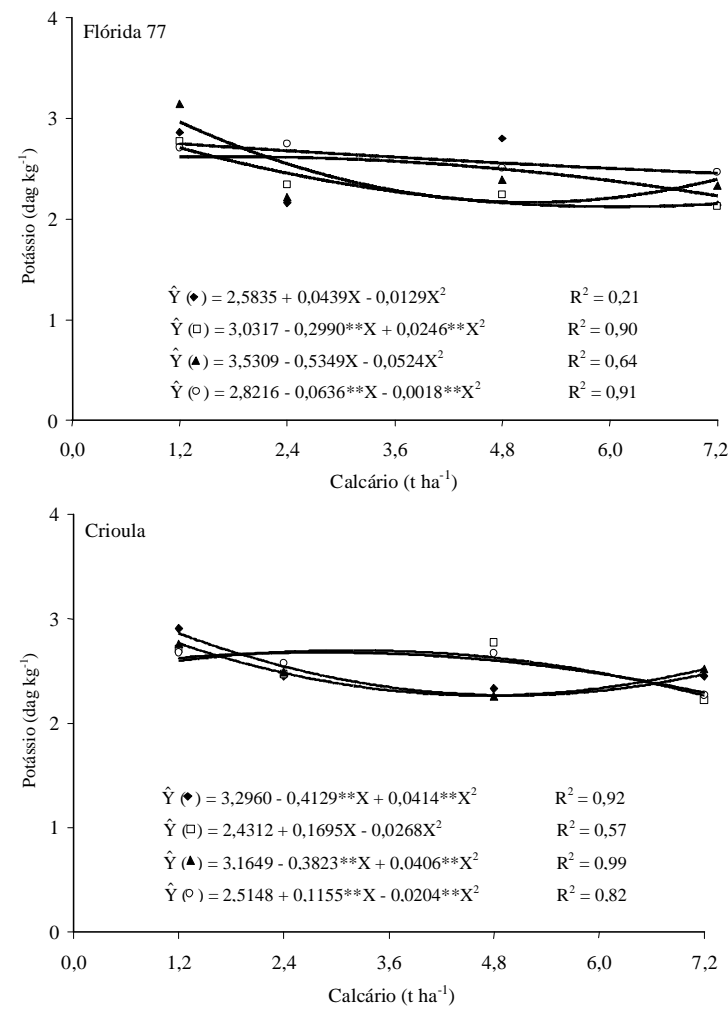

Figura 6. Teores de potássio na parte aérea de alfafa, cultivares Flórida 77 e Crioula, aos 70 dias após a semeadura, em razão das doses de calcário $(\mathrm{X})$ e das relações molares de Ca: $\mathrm{Mg}(\diamond: 100: 0 ; \square: 75: 25 ; \boldsymbol{\Lambda}:$ 50:50; o: 25:75) aplicados ao solo. ${ }^{* *}$ Significativo pelo teste $t$, a $1 \%$ de probabilidade.

\section{Conclusões}

1. A cultivar Flórida 77 é mais exigente em relação à calagem do que a Crioula.

2. A cultivar Flórida 77 apresenta sensibilidade às variações nas relações $\mathrm{Ca}: \mathrm{Mg}$, com maior produção de matéria seca na relação 100:0.

3. A cultivar Crioula apresenta-se mais tolerante a baixos teores de $\mathrm{Ca}^{2+}$ no solo.

4. Mudanças nas doses de calcário influenciam a composição mineral da alfafa.

\section{Agradecimentos}

À Embrapa-Centro Nacional de Pesquisa de Gado de Leite, pelo fornecimento das sementes das culti- 
vares de alfafa; à Embrapa- Centro Nacional de Pesquisa de Agrobiologia, pelo fornecimento da estirpe de Sinorhizobium meliloti.

\section{Referências}

ALVAREZ VENEGAS, V. H. Equilíbrio de formas disponíveis de fósforo e enxofre em dois latossolos de Minas Gerais. 1974. 125 f. Dissertação (Mestrado em Solos e Nutrição de Plantas) - Universidade Federal de Viçosa, Viçosa, MG, 1974.

ALVAREZ VENEGAS, V. H.; RIBEIRO, A. C. Calagem. In: RIBEIRO, A. C.; GUIMARÃES, P. T. G.; ALVAREZ VENEGAS, V. H. (Ed.). Recomendação para o uso de calcário e fertilizantes em Minas Gerais: $5^{\mathrm{a}}$ aproximação. Viçosa, MG: Comissão de Fertilidade do Solo do Estado de Minas Gerais, 1999. 359 p.

ANDREW, C. S.; ROBINS, M. F. The effect of phosphorus on the growth and chemical composition of some tropical pasture legumes I: growth and critical percentages of phosphorus. Australian Journal of Agricultural Research, Melbourne, v. 20, n. 2, p. 665-674, 1969.

BRAGA, J. M.; DEFELIPO, B. V. Determinação espectrofotométrica de fósforo em extratos de solos e plantas. Revista Ceres, Viçosa, MG, v. 21, n. 113, p. 73-85, 1974.

CATALDO, D. A.; SCHRADER, L. E.; YOUNGS, V. L. Analysis by digestion and colorimetric assay of total nitrogen in plant tissues high in nitrate. Crop Science, Madison, v. 5, n. 14, p. 854-856, 1974.

FAGERIA, N. K.; BALIGAR, V. C.; WRIGHT, R. J. Growth and nutrient concentration of alfalfa and common bean as influenced by soil acidity. Plant and Soil, Dordrecht, v. 2, n. 119, p. 331-333, 1989.

FASSBENDER, H. W.; BORNEMISZA, E. Química del suelos con énfasis en suelos de América Latina. San José: Instituto Interamericano de Cooperação para Agricultura, 1994. $420 \mathrm{p}$.

HALSTEAD, R. L.; MacLEAN, A. J.; NIELSEN, K. F. $\mathrm{Ca}: \mathrm{Mg}$ ratios in soil and the yield and composition of alfalfa. Canadian Journal of Soil Science, Ottawa, v. 38, n. 1, p. 85-93, 1958.

HONDA, C. S.; HONDA, A. M. Cultura da alfafa. Cambará: Iara Artes Gráficas, 1990. 245 p.
JOHNSON, C. M.; ULRICH, A. Analytical methods for use in plant analysis. Raleigh: North Carolina State University, 1959. p. 32-33. (California Agriculture Experimental Station Bulletin, 766).

KAMPRATH, E. J. Soil acidity and response to liming. Raleigh: North Carolina State University, 1967. 23 p. (Bulletin, 4).

KELLING, K. A.; MATOCHA, J. E. Plant analysis as an aid in fertilizing forage crops. In: WESTERMAN, P. L. (Ed.). Soil testing and plant analysis. Madison: Soil Science Society of American, 1990. p. 603-643.

LOPES, A. S.; COX, F. R. A survey of the fertility status of surface soils under "cerrado" vegetation in Brazil. Soil Science Society of America Journal, Madison, v. 41, p. 742-747, 1977.

LUND, Z. F. The effect of calcium and its relation to several cations in soybean root growth. Soil Science Society of America Proceedings, Madison, v. 34, p. 456-459, 1970.

MALAVOLTA, E. Elementos da nutrição mineral de plantas. São Paulo: Agronômica Ceres, 1980. 251 p.

MALAVOLTA, E.; VITTI, G. C.; OLIVEIRA, S. A. Avaliação do estado nutricional das plantas: princípios e aplicações. Piracicaba: Potafos, 1997. 319 p.

MARTINS, C. E.; CÓSER, A. C.; OLIVEIRA, F. T. T.; SARAIVA, O. F. Avaliação dos nutrientes limitantes ao crescimento de alfafa em solo aluvial. Revista Brasileira de Zootecnia, Viçosa, MG, v. 19, n. 4, p. 333-339, 1990.

MOORE, D. P.; OVERSTREET, R.; JACOBSON, L. Uptake of magnesium and its interactions with calcium in excised barley roots. Plant Physiology, Rockville, v. 36, n. 3, p. 290-295, 1961.

MOREIRA, A. Efeitos de fontes e doses de fósforo na alfafa (Medicago sativa L.) e centrosema (Centrosema pubescens Benth.) e avaliação de extratores. 1997. 107 f. Dissertação (Mestrado em Nutrição Mineral de Plantas) Escola Superior de Agricultura Luiz de Queiroz, Piracicaba, 1997.

MOREIRA, A.; CARVALHO, J. G.; EVANGELISTA, A. R. Influência da relação cálcio:magnésio do calcário na nodulação, produção e composição mineral da alfafa. Pesquisa Agropecuária Brasileira, Brasília, v. 34, n. 2, p. 249-255, fev. 1999.

MUCHOVEJ, R. M. C.; BORGES, A. C.; NOVAIS, R. F.; THIEBAUT, J. T. L. Effect of liming level and Ca:Mg ratios on yield, nitrogen content and nodulation of soybeans 
grown in acid cerrado soil. Journal of Soil Science, Oxford, v. 37, n. 2, p. 235-240, 1986.

MUCHOVEJ, R. M. C.; BORGES, A. C.; NOVAIS, R. F. Mineral nutrient composition of soybean grown in acid soil as affected by rate and Ca:Mg ratio of the liming material. Revista Ceres, Viçosa, MG, v. 40, n. 228, p. 162-175, 1993.

NUERNBERG, N. J.; MILAN, P. A.; SILVEIRA, C. A. M. Cultivo, manejo e utilização da alfafa. In: NUERNBERG, N. J.; MILAN, P. A.; SILVEIRA, C. A. M. Manual de produção de alfafa. Florianópolis: Empasc, 1990. p. 15-56.

OLIVEIRA, P. D. R.; CORSI, M. Avaliação da produção e da qualidade de cultivares de alfafa (Medicago sativa $\mathrm{L}$.). Revista Brasileira de Zootecnia, Viçosa, MG, v. 16, n. 4, p. 382-393, 1987.

PINKERTON, A.; SMITH, F. W.; LEWIS, D. C. Pasture species. In: REUTER, D. J.; ROBINSON, J. B. (Ed.). Plant analysis: an interpretation manual. Collingwood:
Commonwealth Scientific and Industrial Research Organization, 1997. p. 285-343.

REID, W. S. Influence of lime and calcium:magnesium ratio on alfalfa and birdsfoot trefoil yields. Communications in Soil Science and Plant Analysis, New York, v. 27, n. $5 / 8$, p. $1885-1900,1996$.

SILVA, D. J. Necessidade de calagem e diferentes relações Ca:Mg para a produção de mudas de eucalipto. 1986. 53 f. Dissertação (Mestrado em Solos e Nutrição de Plantas) - Universidade Federal de Viçosa, Viçosa, MG, 1986.

SU, C.; EVANS, L. J. Soil solution chemistry and alfalfa response to $\mathrm{CaCO}_{3}$ and $\mathrm{MgCO}_{3}$ on an acidic Gleysol. Canadian Journal of Soil Science, Ottawa, v. 76, n. 1, p. 41-47, 1996.

VINCENT, J. M. A manual for the practical study of the root-nodule bacteria. Oxford: Blackwell Scientific, 1970. 164 p. (International Biological Programme Handbook, 15). 